\title{
CONTRA O DOGMATISMO REALISTA: NOTAS SOBRE ACORDOS E JOGOS ${ }^{1}$
}

\author{
Marcos Silva ${ }^{2}$
}

\begin{abstract}
Resumo: Este trabalho discute a possibilidade da existência de regras e critérios independentes de nossas práticas discursivas, a partir da filosofia de Brandom e do desenvolvimento filosófico de Wittgenstein. Para tanto, examina-se a normatividade na lógica, no desafio próprio da pluralidade de lógicas náo clássicas, motivando a sua constituição no ambiente social, em função da analogia com jogos. Essa abordagem redunda em uma alternativa pragmatista ao dogmatismo realista. Em vista dessa perspectiva pragmatista baseada na noção de jogos e acordos, defende-se que não é a objetividade do discurso que garante a normatividade de nossas práticas, mas, ao contrário, é a normatividade intrínseca de nossas práticas, seu conjunto de autorizaçóes e proibiçóes que deveria fundamentar a objetividade do discurso.
\end{abstract}

Palavras-chave: Wittgenstein. Brandom. Normatividade. Pragmatismo. Jogos.

\section{INTRODUÇÁO}

É fácil tomarmos a razão como uma autoridade e constatarmos que nós a obedecemos ou, ao menos, que devemos obedecê-la. Contudo, não é nada óbvio determinar o fundamento da autoridade que nos compele a obedecer à razão, mesmo que, de fato, não a obedeçamos ou mesmo que a obedeçamos de maneira inadequada. Afinal, em virtude do que tomamos a razáo como autoridade e nos vemos compelidos a obedecê-la? Qual é a natureza da demanda por justificaçáo? Em virtude do que nos sentimos coagidos pela razão, em nossas práticas discursivas? Afinal, aparentemente, toda atividade

${ }^{1}$ Trabalho desenvolvido com o apoio de uma Bolsa de Produtividade do CNPq.

2 Professor Adjunto do Departamento de Filosofia da Universidade Federal de Pernambuco (UFPE), Recife, PE - Brasil. (D) https://orcid.org/0000-0003-1552-2525 Email: marcossilvarj@gmail.com

https://doi.org/10.1590/0101-3173.2021.v44n3.23.p287

\section{(i)}


de agentes racionais, teórica ou prática, permite justificação ou a demanda por justificação. Em princípio, nós podemos pedir e oferecer razóes em todos os nossos atos. Um agente racional parece entender a demanda pela justificação ou pela razão de um ato, mesmo que ele, de fato, não ofereça ou não entenda a razão do ato.

Neste ensaio, discutiremos a proposta filosófica de se tratar de jogos, ou seja, práticas regradas, e acordos públicos como proposta para se compreender o fenômeno da racionalidade, em geral, e da diversidade de lógicas não clássicas, em particular. A referência teórica que desenvolvemos será a de correntes pragmatistas, especialmente encontradas em Wittgenstein $(1953,1969,1984)$ e Brandom (1994, 2000, 2008). Nessas propostas, entender o caráter social do discurso, no qual normas conceituais são implícitas em nossas práticas, ao invés de suplantar ou inviabilizar a possibilidade da objetividade, é visto como uma alternativa coerente e promissora para se tornar tal objetividade, de fato, inteligível. Tomamos essa proposta como pragmatista, porque compreende nossas atividades racionais, a (possibilidade de) correção e a objetividade de nossos discursos como fundadas na e pela normatividade das regras internas e públicas que acompanham, orientam e constituem nossas práticas, inclusive nossas práticas inferenciais.

O fio condutor da discussão é o reconhecimento de demandas normativas, em uma comunidade de indivíduos engajados em práticas públicas, como fundamento da objetividade do discurso, a partir de uma reação crítica ao dogmatismo realista. Em outras palavras, o eixo de recusa de uma esfera impessoal independente de nossas atividades, o que caracteriza o dogmatismo de vertente realista, determina que a objetividade seja justificada nas próprias práticas, ou seja, internamente aos nossos acordos e usos linguísticos, com base na estipulação de quadros de referência que viabilizam correçôes de aplicaçóes desviantes. Devemos, por conseguinte, nesse horizonte, reconhecer a centralidade das noçóes de regras, normas, critérios e medidas em uma filosofia que pretenda fundamentar a razão dentro de uma tradição pragmatista inspirada em Brandom e no assim chamado segundo Wittgenstein.

Este ensaio é dividido em duas seções. Na primeira, como alternativa ao dogmatismo realista, discute-se a possibilidade da existência de regras e critérios independentes de nossas práticas discursivas, a partir de Wittgenstein e Brandom. A segunda seção examina a normatividade na lógica, especialmente em um cenário contemporâneo de grande diversidade de lógicas que desafiam o cânone clássico, motivando a sua constituição no ambiente social, em 
função da analogia com jogos. Defendemos, através de uma abordagem pragmatista baseada na noção de jogos e acordos, que não é a objetividade do discurso que garante a normatividade de nossas práticas, mas, ao contrário, é a normatividade intrínseca de nossas práticas que deveria fundamentar a objetividade do discurso.

\section{Existe uma Regra indePendente de nOSSAS Práticas? Sobre a NATUREZA NORMATIVA DE NOSSOS CRITÉRIOS}

A objetividade das noçóes normativas deve ser explicada, numa abordagem pragmatista, em razão de acordos públicos e objetivos (mas, muitas vezes, tácitos) entre indivíduos em uma comunidade. Em uma proposta pragmatista da racionalidade, a objetividade do discurso pode (e deve) ser pensada sem um objeto designado, ou seja, não ancorada em algum domínio independente de coisas, sejam elas abstratas, sejam físicas. Consequentemente, essa abordagem se desenvolve desde a crítica à visão de que um ser racional deveria ser pensado como algum tipo de substância representando verdadeira ou falsamente o mundo, com base em seus conteúdos mentais, como em uma tradição marcadamente cartesiana. Essa tradição é desafiada por várias vertentes do pragmatismo, pela concepção de que um ser racional deve ter capacidades para se engajar (deontologicamente) em práticas discursivas, em um ambiente dinâmico de interaçôes materiais com outros seres (RORTY, 1979; BRANDOM, 1994). "Deontologicamente" aqui é fundamental, por marcar a constituição de nossas práticas racionais, não na determinação de verdades em relação a uma realidade independente, como preconiza o dogmatismo realista, mas na possibilidade do reconhecimento de um quadro denso de proibiçôes e autorizaçôes articuladas em nosso engajamento cotidiano em práticas regradas.

É importante notar que alguma noçáo de medida radicalmente independente de comunidades parece fazer pouco sentido. Podemos nos perguntar o que seria um critério real, isto é, um critério independente de agentes. Em outras palavras, a pergunta que se impóe, nesse enfrentamento do dogmatismo realista, dada a centralidade da noção de regras na constituição de uma perspectiva pragmatista da racionalidade, é esta: é possível haver uma regra independente de indivíduos para reconhecê-la como norma de práticas e, eventualmente, segui-la ou mesmo sem agentes racionais para serem corrigidos, se não segui-las? Faz sentido haver regras reais, independentes de 
atividades de agentes racionais, no "mundo bruto" de fatos? Em um raciocínio contrafactual, se não houvesse agentes racionais, haveria regras no mundo? Se seres humanos, por exemplo, com suas instituiçóes e atividades discursivas se extinguissem, o mundo ainda conteria normas?

Para tais perguntas, a resposta apropriada de um pragmatista deveria ser negativa, uma vez que um critério ou regra fundamentalmente natural, ou seja, um critério ou regra no mundo independente de indivíduos em comunidades faz tanto sentido quanto a ideia de um critério radicalmente privado, cuja aplicaçáo náo pudesse ser corrigida e que não pudesse ser ensinado para ou compreendido por ninguém além do seu autor. Rejeita-se, dessa forma, uma espécie de platonismo de regras, em que nossas atividades discursivas apenas representam ou espelham uma estrutura normativa da realidade, independente de seres racionais. Para um plantonista de regras, exemplo de dogmatismo realista, nossos sistemas de proibiçóes e autorizaçóes, os quais constituem nossas práticas regradas e públicas, encontrariam sua fundamentação não nas práticas propriamente dita, mas na representação de estruturas deontológicas existentes independentemente da existência de qualquer agente racional. Nessa visão dogmática, a legitimidade de nossas regras estaria na concordância destas com essas estruturas deontológicas independentes da nossa própria capacidade de representá-las.

É importante notar, nesse horizonte de investigação, que critérios para avaliação de nossas atividades teóricas e práticas são instâncias abstratas, mas objetivas de referência, em contextos discursivos, e que, além disso, precisam ser fixados. Uma vez estipulados ou instituídos para avaliarmos nossas práticas, critérios não precisam ser definitivos ou intocáveis, todavia, devem desempenhar o papel de referências suficientemente estáveis para avaliarmos nossas descriçôes, açóes e inferências. Esse papel paradigmático de referência para nossos julgamentos teóricos e práticos redunda na objetividade suficiente para nossas práticas discursivas. Afinal, o que significaria uma noção de medida absolutamente transcendente? É necessário se estipular a existência de quadros de medida e de referência completamente independentes de atividades de agentes racionais? Por outro lado, o que seria uma medida que muda recorrentemente, ao longo do próprio processo de medição? Em que medida um critério poderia variar, em cada circunstância de aplicaçáo e ainda assim ser considerado um critério?

É razoável pensar que um sistema de referência muito instável não seria tomado sequer como um sistema de referência para avaliarmos coisas e práticas. 
Um critério, por exemplo, que muda arbitrariamente em cada instância de aplicação náo seria considerado um critério por nós. Assim, parece-nos tão absurdo esperarmos encontrar uma medida, um critério ou um sistema de referência "puro", isto é, radicalmente real no mundo e independente de agentes racionais, quanto também supormos que possa haver um sistema de referência completamente instável e variante, a cada aplicação.

Interessantemente, alguns tópicos diretamente relacionados com essa discussão de normatividade fundante da objetividade de nossas práticas discursivas emergem na filosofia de Wittgenstein, já no começo da década de 1930. Esse desenvolvimento pode ser acompanhado nas anotaçóes de Waismann (WITTGENSTEIN, 1984, doravante, WWK) e foi desenvolvido por alguns autores, como Hacker (1986, 2013) e Engelmann (2013a, 2013b). No começo da década de 1930, o autor do Tractatus começa a usar relevante e originalmente, em seu desenvolvimento filosófico, a noção de jogos, para entender práticas matemáticas e lógicas. Como consequência, as noções de autorização e proibiçôes parecem ganhar centralidade nas discussóes sobre lógica e linguagem. Não há discussóes relevantes sobre autorizaçôes e proibiçóes, no Tractatus, no contexto da lógica e da matemática. exemplo:

Wittgenstein, em discussóes com o Círculo de Viena, afirma, por

Resumindo, você poderia dizer que a conexão vero-funcional entre proposiçôes forma uma parte da sintaxe. As regras que eu mostrei naquele tempo [do Tractatus] são agora restritas pelas regras que originam a sintaxe interna das proposiçóes e proíbem proposiçôes de atribuir diferentes coordenadas à realidade. Todas as funçóes de verdade que náo forem proibidas por estas regras são permitidas. ${ }^{3}$ (WWK, p. 80).

Como apontado, esse tipo de vocabulário deontológico, marcado por proibiçóes e autorizaçóes, em seu retorno à filosofia, está, reveladoramente, ausente no Tractatus. Depois de alguns problemas com seu atomismo lógico (HACKER, 1986; ENGELMANN, 2013), Wittgenstein parece notar que operadores lógicos deveriam ser topicamente sensíveis ao sistema que eles expressam (CUTER, 2017). Nós deveríamos testar ou verificar a possibilidade da formação molecular de algumas proposiçóes, uma vez que a formação de algumas proposiçóes complexas não seria permitida. Algumas construçóes proposicionais complexas deveriam ser proibidas. A livre distribuição de

3 Todas as traduçōes deste trabalho são de minha responsabilidade. 
valores de verdade, independentemente da existência de nomes vazios, deveria ser restrita ou proibida em alguns sistemas organizados conceitualmente, ou seja, permeados e constituídos por relaçôes inferenciais de incompatibilidade (SILVA, 2020). Note-se que aqui já estamos usando vocabulário normativo, baseado em autorizaçóes e proibiçôes, para entender como operadores não neutros, ou seja, não verofuncionais, deveriam funcionar.

O que parece ficar claro para Wittgenstein, já no começo da década de 1930, ao abandonar o seu atomismo lógico (SANTOS, 2001, 2011), é que sistemas de referência devem ser introduzidos, estipulados, constituídos por indivíduos, isto é, agentes racionais em suas práticas em comunidades (SILVA, 2013; CUTER, 2009; ENGELMANN, 2013a, 2013b). E, por conseguinte, esses mesmos sistemas de referência, como sistemas de critérios de avaliação e correção de nossas atividades discursivas, não precisam se basear em qualquer realidade independente de nossas próximas atividades discursivas elas mesmas. Uma vez instaurados publicamente, esses sistemas de referência (Maßstäbe) ganham força normativa, ou seja, ganham papel objetivo de referência e correção de nossas atividades e, portanto, não precisam ser tomados nem como verdadeiros e nem como falsos, por não serem descrições ou representações de estruturas independentes. Esses sistemas estipulados determinam o quadro de critérios pelos quais avaliamos coisas, outras práticas, representaçôes ou descrições, como verdadeiras ou falsas.

Com efeito, Cuter articula a discussão sobre lógica com o papel normativo de sistemas de referência como sistemas de medidas e defende:

Ou objetos destacados do mundo, como o metro padrão de Paris (ou, para todos os efeitos práticos, a régua que está em minha gaveta) são incorporados à linguagem munidos de suas escalas graduadas e dos números que associamos a elas, ou será impossível encontrar uma expressão linguisticamente articulada para os resultados da medida que preserve as relaçóes lógicas relevantes existentes entre estes resultados. Uma parte inescapável no processo de formaçấo do sentido se dará, entấo, no contexto de operaçôes tão corriqueiras quanto medir, sem poder dispensar o auxílio de objetos táo intramundanos quanto uma régua graduada e as regras que arbitrariamente fomos associando, no curso da história humana, ao seu uso. A generalização deste modelo para toda a linguagem e a extração de todas as consequências dessa generalizaçáo fornecem, a meu ver, o motivo condutor da filosofia madura de Wittgenstein. (CUTER, 2009, p. 192). 
Devemos concordar com Cuter que a generalização desse modelo apresentado no começo da década de 1930 para toda a linguagem e a extração de todas as consequências dessa generalização fornecem o motivo condutor da filosofia madura de Wittgenstein. Entretanto, vale notar que o apelo radicalmente antropológico, quer dizer, vinculado a práticas humanas, e dinâmico de regras e sistemas de referência gera certo desconforto filosófico em função de inevitáveis consequências convencionalistas desde a Grécia Antiga.

Sem a devida ênfase na noção de normatividade e a consequente noção de objetividade fundada em quadros de proibiçóes e autorizações de nossas práticas regradas, acreditamos que a proposta pragmatista, isto é, a proposta que visa a fundar a racionalidade em nossas práticas e usos, e não em domínios transcendentes e nem em aspectos redutíveis a fatos físicos da realidade, com efeito, redundaria em um convencionalismo difícil de ser defendido. Parece que, se perdermos o fundamento na realidade última das coisas, como o dogmatismo realista sustenta, ou mesmo em alguma estrutura cognitiva a priori e universal, como kantianos defendem, a possibilidade da fundamentaçáo da racionalidade redundaria apenas em convençóes arbitrárias e vazias de indivíduos. Uma resposta convencionalista ao problema da objetividade do discurso parece ser inadequada também, em função da arbitrariedade e subjetividade na escolha e estipulação, por exemplo, dos sinais gráficos de uma atividade discursiva.

Assim, é importante evitarmos a armadilha convencionalista. Deve-se observar que a disjunção exclusiva, por exemplo, entre sinais convencionados em uma folha de papel ou sons de origem arbitrária do discurso e o significado desses sinais, pela referência obrigatória a entidades abstratas e impessoais independentes de nossas práticas, podem ser tomados como um falso dilema. Estas não são as duas únicas alternativas: negar uma não significa ter que aceitar a outra. Negar a convencionalidade pura dos sinais de nosso discurso náo implica afirmar a necessidade de entidades abstratas e impessoais independentes de nossas práticas, para ancorar nossas atividades discursivas. Devemos pensar no significado e na importância filosófica de acordos e normas, muitos deles tácitas, nesse contexto, enfatizando o caráter construtivo, social, público e objetivo das noções de critério, medida e regras e seu papel na constituição da objetividade do discurso.

De acordo com uma abordagem pragmatista, inspirada em Brandom e no segundo Wittgenstein, a distinção entre proposições empíricas e proposições lógicas não deveria ser o seu conteúdo, e nem a sua forma lógica, mas sim o seu 
papel normativo em nossa imagem de mundo, isto é, em nosso entendimento teórico e prático do mundo e de como ele opera. Proposiçóes empíricas podem igualmente, em alguns contextos, e sob algumas circunstâncias, desempenhar o papel de normas para nossas práticas, uma vez que podem ser usadas, por exemplo, para corrigir nossa percepção ou guiar nossas açóes e investigaçôes.

Assim, a normatividade da lógica, em específico, e da racionalidade, em geral, não deve ser pensada como um subproduto ou consequência marginal da racionalidade, todavia, é central para o entendimento da dinâmica de nossas práticas e a natureza da necessidade lógica. Devemos notar que os princípios lógicos, em uma abordagem antirrealista, ou seja, em uma perspectiva que rejeita frontalmente o dogmatismo realista acerca da existência independente de estruturas, para justificar a objetividade e racionalidade de nosso discurso, estão mais próximos de princípios éticos que de leis da ciência, já que esses princípios não precisam ser usados para descrever nenhum fato da realidade, mas devem guiar normativamente nossas decisóes, comportamentos e como nós avaliamos a qualidade de nossas práticas e açóes. Agentes racionais não precisam criar convencionalmente fatos, contudo, precisam regularmente estabelecer os critérios que são usados para descrever fatos e avaliar a qualidade de nossas descriçóes de fatos, por exemplo.

O problema não é que tudo se segue a partir de nossa vontade, como em uma proposta convencionalista. A importância do arbítrio individual diminui, na medida em que o número de participantes em uma prática aumenta e se complexifica. Aqui tudo se passa como se nós não pudéssemos argumentar nem a favor e nem contra escolhas para regras muito básicas de nossas práticas, por exemplo, como poderíamos argumentar a favor ou contra um passo dado em um raciocínio dentro de um sistema; nós só poderíamos aceitar ou rejeitar regras muito básicas; nós deveríamos, sim, ser instruídos e educados a usar algumas regras. A abordagem pragmatista aqui não é convencionalista, porque é baseada na introdução de critérios e regras públicas e objetivas e não em escolhas arbitrárias e subjetivas, para avaliar nossas práticas.

Wittgenstein, já na década de 1930, sugere que o espaço lógico deve ser eingeengt (limitado, restrito) por regras especiais para a sintaxe interna das proposiçóes elementares que proíbem algumas combinaçóes moleculares (WWK, p. 80). O que não é proibido por essas regras é permitido. Intuitivamente, não faz sentido falar de regras, quando todas as combinaçóes e possibilidades são autorizadas ou quando, por assim dizer, nenhuma liberdade, ou espaço de manobra, é limitado. Uma regra significa, entre outras coisas, 
restringir um espaço de possibilidades, de atividades, de ações, um Spielraum (SILVA, 2020).

Uma outra referência histórica relevante no desenvolvimento da filosofia de Wittgenstein é a, muitas vezes esquecida, discussão que Waismann e Wittgenstein estâo tendo sobre o Grundgesetze II (FREGE, 1903/1959), documentada na entrada "Was in Könisbergzu sagen wäre”, do WWK. A metáfora de jogos, ou seja de práticas regradas articulando internamente a objetividade de nossas atividades discursivas, a qual só começa a ser pensada seriamente nessa altura na filosofia de Wittgenstein, tem sua origem, ironicamente, no platonista Frege, ou melhor, na discussão crítica de Frege sobre a filosofia da matemática defendida por alguns formalistas contemporâneos a ele. A discussão de Wittgenstein com Waismann, em Viena, a respeito de Frege, é fundamental para nossa visão, porque exibe o argumento a ser desenvolvido por pragmatistas contra o dogmatismo realista, qual seja: Wittgenstein, ao ler os parágrafos 88-137 de Grundgesezte II, apresenta as críticas deste aos formalistas, também como um falso dilema (WWK, p. 105).

Frege, segundo Wittgenstein, mostra uma posiçáo inadequada, porque em matemática e em lógica não se trata ou bem de sinais físicos e convencionais no papel ou bem de um Bedeutung abstrato, para além do espaço e do tempo, independente de nossas práticas e inerte causalmente. $\mathrm{Na}$ verdade, não precisamos do Bedeutung independente de nossas práticas preconizado pelo dogmatismo realista, adverte Wittgenstein, porque temos os sinais físicos na folha de papel mais as regras de manipulação desses sinais introduzidos por práticas cooperativas em uma comunidade de indivíduos. Essa esfera antropológica e social, nas práticas discursivas, parece ter sido notada por Wittgenstein, ao reagir criticamente ao dogmatismo realista, tanto o de tipo platonista de Frege quanto o seu próprio, desenvolvido no Tractatus (1921).

Essa primeira discussão pragmatista no interior da discussão da filosofia da matemática parece ser desenvolvida e generalizada no interior do desenvolvimento da filosofia de Wittgenstein. Em verdade, ao enfatizarmos o aspecto normativo da racionalidade, raízes dessa discussão podem ser encontradas também no desenvolvimento da investigação de Santos (2013), em relação à disputa clássica entre retórica e dialética. Há, nessa discussão, inclusive importantes consequências políticas, além de metafísicas e epistemológicas, ao se desqualificar o dogmatismo realista e introduzir, nesse contexto, a noção de "jogo de influências". Assinala Santos (2013, p. 262): 


\begin{abstract}
No embate entre retórica e dialética pela primazia no domínio das artes de argumentar, confrontam-se duas concepçôes do que seja a comunicação racional entre os homens. Para os campeóes da retórica, é racional a comunicação por meio da qual uma opinião se sobrepóe a outras pela persuasão discursiva, pela aceitação espontânea do discurso do orador por um auditório. Racional não é a comunicação que visa a submeter os ouvintes a uma suposta verdade revelada pelo orador, que supostamente a compartilharia com os ouvintes (o modelo pedagógico), nem a que visa a depurar os discursos dos interlocutores de seus componentes pessoais, subjetivos, a fim de desentranhar uma verdade impessoal (o modelo dialético), mas a que visa a produzir o consenso espontâneo sobre um discurso comum, resultado de um jogo de influências livremente assimiladas, no modo da persuasão, de uns sobre os outros (o modelo retórico).
\end{abstract}

$\mathrm{Na}$ abordagem pragmatista do presente trabalho, devemos concordar com Santos (2013), quando defende que a retórica náo passa ao largo da verdade, mas deveria se concentrar na constituição intersubjetiva de verdades comuns a muitos. À retórica caberia tecer verdades comuns na base do jogo das verdades individuais, sem que, para isso, possa ou deva recorrer a qualquer esfera impessoal, anterior à interação entre os homens, independente de nossas práticas discursivas, fora do tempo e do espaço e inertes causalmente.

Assim, Santos, ao examinar, por exemplo, como Górgias deveria terse defendido contra o dogmatismo realista de Sócrates, sem ter que admitir um relativismo ou subjetivismo radical, defende o papel fundamental desempenhado por acordos de indivíduos engajados em uma prática social, para determinar o que é bom e justo, destacando a relação de nossas práticas com a constituição da racionalidade e da objetividade de nosso discurso como um fenômeno eminentemente social. Nessa abordagem, Protágoras seria um wittgensteiniano avant la lettre (SILVA, 2015).

Nessa leitura pragmatista, agentes racionais devem poder convergir em um discurso comum, e essa convergência não pode ser determinada por nenhuma outra esfera mais fundamental, como, por exemplo, a convergência fundada na pretensa apreensão das coisas últimas da realidade, conforme elas supostamente são em si e por si mesmas. É possível uma alternativa ao dogmatismo realista independentemente de nos comprometermos com a estipulação de estruturas a priori e universais da cognição humana. 
Com essa estratégia antropológica e normativa proposta por Santos, Górgias, por exemplo, não teria tido dificuldade em defender a retórica como arte suprema, dotada ainda de valor racional e moral, uma vez que

[...] não se pode pretender, por meio do discurso, revelar a outrem um conteúdo que fosse compartilhável. $\mathrm{O}$ que se pode pretender, por meio da interação discursiva entre indivíduos, é a produção de um consenso com respeito a um discurso, a adesão dos interlocutores a um discurso comum. A comunicação pela linguagem não pode ser mais que uma interação entre pessoas que buscam umas alterar o domínio das aparências e crenças das outras, a fim de se obter um acordo quanto a discursos que mereçam a adesáo de todos e quanto às açóes desencadeadas por essa adesão. (SANTOS, 2013, p. 261).

Contemporaneamente, o inferencialismo de Brandom (1994, 2000, 2008) também é uma proposta filosófica que avança discussóes pragmatistas e antropológicas, destacando a esfera da normatividade na constituiçáo da racionalidade. Em Brandom, não é a objetividade do discurso que garante a normatividade de nossas práticas, mas, ao contrário, é a normatividade intrínseca de nossas práticas que deveria fundamentar a objetividade do discurso. Pelo inferencialismo de Brandom, vemos como desenvolver o tipo de pragmatismo do segundo Wittgenstein, a partir de sua crítica ao falso dilema de Frege. A ênfase dada à noção de jogo implica a necessidade de se pensar nossas atividades discursivas como práticas regradas constituídas a partir de quadros de proibiçóes e autorizaçóes que fundamentam os critérios pelos quais julgamos a qualidade de nossas descriçóes e julgamentos.

\section{DIVERSIDADE DE LÓGICAS: NORMATIVIDADE E SUA NATUREZA SOCIAL}

O programa intuicionista de Brouwer, como apresentado em sua histórica tese de doutorado e, também, em seu artigo "The Unreliability of the Logical Principles" (1908), mostra uma motivação filosófica para a revisão de princípios lógicos e não somente para inovaçôes de engenharia na manipulação regrada de símbolos e na introdução de uma pletora de cálculos formais. Brouwer sustenta que devemos revogar a validade universal e irrestrita do princípio do terceiro excluído, bem como rejeitar provas indiretas. Nos sistemas intuicionistas de Heyting (1928), por exemplo, uma inferência só é válida, se uma construção puder ser elaborada, a qual torne verdadeira a fórmula obtida ao aplicarmos uma regra aceita no sistema. Nessa visão, 
o que os princípios da lógica deveriam preservar náo deveria ser, como em uma interpretação realista e dogmática da lógica clássica, uma verdade independente de mentes e de atividades cognitivas, mas construtibilidade. Logo, vários princípios da lógica clássica, mais notadamente o princípio do terceiro excluído, deveriam ser tomados como insuficientemente fundados.

A falta de fundamento razoável para o princípio clássico da explosão também evidencia razōes importantes para a revisão de princípios lógicos, porque deveria ser problemático derivar qualquer sentença possível de uma contradição (DA COSTA, 1958, 1959, 1974). Na lógica clássica, é suficiente ter uma contradição, para que isso redunde em uma relação de consequência lógica explosiva e trivial no sistema. Com efeito, nosso problema em domínios racionais não deveria ser a existência de contradições, mas sim a ocorrência de uma relação explosiva de consequência lógica. Nós deveríamos, por conseguinte, distinguir trivialização de contradição (MARCOS, 2004, 2010).

Em algumas discussôes racionais ou em alguns domínios importantes de nossas vidas, quando nós lidamos com crenças e informaçôes, por exemplo, nós, de fato, encontramos contradiçóes e mesmo assim continuamos raciocinando, sem a demanda irreal de nos comprometermos com qualquer outra crença, especialmente com as estapafúrdias (CARNIELLI; RODRIGUES, 2015, 2016, 2017, 2019a, 2019b). Além disso, vale notar que algumas teorias na ciência poderiam ser inconsistentes, sem serem triviais (PRIEST; TANAKA; WEBER, 2015).

Essas objeçóes filosóficas para a natureza e o escopo da ortodoxia clássica pavimentaram o caminho para a emergência de, pelo menos, duas lógicas alternativas à lógica clássica, respectivamente, a lógica intuicionista e a paraconsistente. Essas famílias de diversas lógicas possuem importantes implicaçóes filosóficas e técnicas para a matemática e, também, para a computação.

Por conseguinte, nós deveríamos tomar a pluralidade de lógicas não clássicas como uma questão filosófica séria, isto é, como algo que demanda uma explicação filosoficamente bem-formada e nos força a reconsiderar o papel e o propósito da lógica. Duas visóes extremas impediram o caminho para nos engajarmos com as consequências e pressupostos filosóficos da pluralidade de lógicas alternativas. Por um lado, uma visão, que se alinha ao dogmatismo realista, tomaria a lógica como algum tipo de investigação ou empreendimento metafísico o qual poderia nos oferecer ferramentas intelectuais sofisticadas, 
para descobrirmos estruturas abstratas independentes de nossas atividades cognitivas, fora de nossas mentes, na realidade última das coisas.

Do outro lado do espectro, outra posição convencionalista manteria que a lógica é basicamente um jogo vazio de conteúdo governado por decisóes e regras arbitrárias e ad hoc. A visão pragmatista delineada na primeira parte deste trabalho aponta para uma via intermediária para explicar a natureza e normatividade da lógica no horizonte de uma pluralidade de sistemas que desafiam frontalmente a lógica clássica.

Acreditamos que podemos entender o cenário desses problemas filosóficos quanto à normatividade da lógica dentro do contexto da grande multiplicidade contemporânea de sistemas que desafiam o cânone clássico, aplicando a nossa discussão da seção anterior.

Em sua obra, Brandom, por exemplo, enfatiza o caráter inferencial do significado. O inferencialismo semântico preconiza que os conceitos só ganham significado, caso articulados inferencialmente em quadros de compatibilidade e incompatibilidade com muitos outros conceitos (BRANDOM, 1994, 2000). Como consequência dessa abordagem, na sua filosofia da lógica, são priorizadas, por exemplo, abordagens baseadas em teoria da prova com a definição do significado de conectivos lógicos pelas regras de introdução e eliminação, ao invés do representacionalismo próprio da teoria dos modelos contido na noção de satisfação, para investigar a relação de consequência lógica em sistemas formais.

Em sua versão normativa e pragmatista do inferencialismo, um agente racional, por exemplo, ao afirmar $\mathrm{p}$, assume um compromisso com a verdade do enunciado e com a possibilidade de justificá-lo. A natureza desse compromisso é claramente deontológica, já que a asserção como um ato de fala insere o indivíduo em um quadro de obrigações, autorizaçóes e proibições. Nesse horizonte, Brandom associa a polêmica entre um pragmatista e um realista dogmático, com a controvérsia entre um lógico construtivista e um clássico, explicitamente desenvolvendo argumentos de Dummett (1991), a favor de semânticas construtivas (embora não intuicionistas, necessariamente).

Vale notar que semânticas construtivas adotam como noção básica, para a elucidação do conceito de sentido, a noção antirrealista de "condiçóes de assertabilidade", no lugar da noção semanticamente realista de "condiçôes de verdade". Assim, compreender o sentido de um enunciado é compreender 
as condiçóes sob as quais o enunciado pode ser corretamente asserido e não suas condiçóes de verdade.

Ao insistir que o uso, o sentido e o significado em linguagens só podem ser entendidos no contexto social de nossas práticas, ou seja, ao ancorar a normatividade e objetividade de nossas atividades discursivas em práticas sociais, Brandom articula a troca de informação na comunicação racional com ações de indivíduos em interações dinâmicas em uma comunidade e não com crenças e representaçóes de um sujeito pensante, a respeito de alguma realidade independente. Por exemplo, no capítulo 3 de sua seminal obra Making it Explicit (1994), Brandom introduz o jogo de oferecer e pedir razóes como uma explicação para o que nos torna animais sociais, linguísticos e racionais. Como Brandom defende, as práticas desse jogo, ou prática regrada, de oferecer e demandar razôes são fundamentalmente normativas. Com efeito, a propriedade de lances ou jogadas dos jogadores (agentes) e a possibilidade (constitutiva) de correçôes mútuas e do mútuo reconhecimento de autoridade são passos centrais em sua explicação da normatividade. ${ }^{4}$

Como consequência para nossa discussão a respeito do dogmatismo realista, uma prática racional não seria nem uma atividade que representasse alguma estrutura transcendente e eterna, nem uma prática redutível a regularidades físicas e nem requereria algum juiz fora do jogo, legislando a correção das jogadas. A proposta de Brandom é filosoficamente atraente, em sua motivação pragmatista, por fazer a correção das jogadas ser de responsabilidade dos jogadores eles mesmos. Os indivíduos engajados na prática determinam se a "jogada" é apropriada ou não, em função de critérios públicos internos ao jogo e ao se corrigirem mutuamente. Essa abordagem brandomiana se alinha bem ao contexto de discussão do Protágoras de Santos (2013) e do Wittgenstein das anotaçóes de Waismann (1930).

O ponto crucial é que nós não somos racionais porque somos criaturas que manipulam representaçóes que estâo insularizadas em nossas mentes, mas nós somos organismos que operam e lidam com objetos no mundo, a partir de regras e acordos públicos, porém, muitas vezes tácitos. Nossas mentes não são veículos de representaçóes a serem aperfeiçoadas, porém, uma capacidade a ser educada. Nossas atividades racionais não são espelhos que são tão bons quanto melhor ou mais fidedignamente puderem representar a realidade fora de si, contudo, deveriam funcionar como lâmpadas a iluminar ou explicitar o

\footnotetext{
${ }^{4}$ Vale notar a inspiração de Brandom, na visão normativa da cooperação comunicacional, como introduzida e defendida seminalmente por Lewis (1979).
} 
que nós já sabemos fazer em nossas práticas cotidianas, permitindo o controle público de desvios e a possibilidade de revisão (RORTY, 1979; BRANDOM, 1994). Nesse sentido, os princípios e regras mais básicos de uma lógica devem ser tomados não como representando alguma realidade transcendente, mas como expressando ou explicitando acordos tácitos em práticas de indivíduos em uma comunidade. E porque esses acordos tácitos podem apresentar muitas características de raciocínios não clássicos, sistemas formais não clássicos são engajados para expressá-los (BRANDOM, 1994, 2000).

Vale notar que Kant já havia apontado o, por assim dizer, caráter disposicional do julgamento como fundado em uma capacidade humana a ser treinada, e não como um atributo de uma substância imaterial pensante (HACKER, 2013). Um dos grandes desafios interessantes na discussão sobre o conceito de racionalidade, desde o idealismo transcendental de Kant até os pragmatistas contemporâneos, é desvincular a noção de objetividade da noção de algum objeto independente. Podemos, sim, ter objetividade sem termos que nos engajar com ou pressupormos estruturas ou domínios independentes de nossas práticas ou de atos de um sujeito, como preconiza o dogmatismo realista. O idealismo transcendental de Kant e o, digamos, construtivismo social de Wittgenstein e Brandom são tentativas nesse sentido. A distinção aqui é a de que o que era transcendental e garantido por categorias e formas de um sujeito transcendental, para Kant, é tomado como social, para o assim chamado Wittgenstein maduro e para Brandom. Em outras palavras, a transcendentalidade deveria ser fundada por acordos tácitos entre indivíduos de uma comunidade, em suas interaçóes materiais.

É oportuno observar que qualquer progresso racional ou científico deveria ser o efeito de uma adesão aos critérios, apoiada por dinâmicas retóricas entre indivíduos de uma comunidade similar a uma conversão. Os princípios mais gerais da razão não são descobertos, mas também não são escolhidos; eles devem ser consolidados e aprendidos ao longo de um histórico complicado de interaçóes dinâmicas e retóricas entre indivíduos. Nessa espécie de construtivismo pragmático, não há padrão mais alto de objetividade que o assentimento dos membros de uma comunidade.

Dessa forma, o paradigma pragmatista deve ser visto como uma mudança do foco filosófico, das coisas, como representaçôes internas e conteúdos mentais, para a preocupação com atividades, como o ato de representar e julgar, a partir de regras, sobre os fatos do mundo. Tais atividades são, com frequência, corporais (embodied), porque envolvem essencialmente 
trocas de um indivíduo situado e limitado com o mundo. Assim, por exemplo, uma versão do problema da intencionalidade, sob essa perspectiva, parece pouco relevante, como a pergunta a respeito do que torna $A$ uma representação de B. O que deve ser discutido, na visão pragmatista, em uma radical rejeição do representacionalismo e do dogmatismo realista, é: quais formas nossas atividades de representar tomam e como elas possuem as consequências materiais que possuem, com base na aplicação de critérios públicos de avaliação e correção de casos desviantes. Os enativistas Myin e Hutto (2013, p. 153) afirmam: "[...] o ponto importante aqui é que as atividades acopladas são a base para as atividades desacopladas, e não o inverso."

Nós devemos poder aplicar esse modelo de racionalidade pragmatista na discussão da natureza da lógica também, visto que lógica, ou melhor, nossas práticas inferenciais são partes integrais do que chamamos de atividade racional. Em especial, como vimos, nossos sistemas lógicos devem ser pensados, nessa tradição pragmatista, como surgindo de reflexôes sobre certos aspectos de nossas práticas inferenciais. Quando refletimos teoricamente sobre nossas práticas e, especialmente, sobre nossas práticas dedutivas, essas práticas podem ser (e normalmente são) afetadas por nossas reflexóes. A relação entre nossas práticas e nossas teorias sobre essas práticas é uma via de mão dupla: algumas vezes, avaliamos, confirmamos ou revogamos teorias, por seu acordo ou desacordo com as práticas; outras vezes, revisamos aspectos de nossas práticas, a partir de consideraçóes teóricas. Como ressalta Pereira (2006, p. 97), “[...] nossas práticas náo são sacrossantas: determinadas açóes ou argumentos, antes tidos como moralmente aceitáveis ou corretos, podem ser reavaliados sob uma nova luz lançada por nossas teorias sobre essas açóes e argumentos."

Dessa forma, no paradigma pragmatista, devemos notar que, ao tratarmos de sistemas formais, estamos tratando de sistemas que explicitam, mostram ou, simplesmente, expressam o que nós já usamos em nossas práticas, ao proibirmos ou permitirmos alguns passos ou lances em nossos jogos ou, mesmo, ao adotarmos alguns passos inferenciais como corretos e outros como incorretos - e nos corrigimos e a outros, em função desses mesmos parâmetros.

Nesse sentido, é importante destacar a pertinência da noção de cálculos lógicos como jogos para enfrentar problemas contemporâneos em filosofia da lógica, como o fenômeno da profusão de lógicas não clássicas. A tentativa de compatibilizar o pluralismo lógico, ou seja, a tese filosófica que defende a existência de mais de um sistema lógico correto para modelar um domínio de coisas, com uma visão única e integrada de racionalidade, parece 
ser um dos grandes desafios na discussão contemporânea sobre filosofia da lógica (BEALL; RESTALL, 2000, 2001 e 2006; SHAPIRO, 2014). Não é nada claro como poderíamos nos valer de filósofos clássicos que pensaram na natureza da racionalidade, a partir do dogmatismo realista, para interpretar nosso momento atual. Uma maneira tradicional de se fundar filosoficamente princípios da lógica é tomá-los como leis que seriam necessárias, universais e autoevidentes. Essa estratégia parece, hoje, extremamente insatisfatória, por diversas razões.

Como poderíamos racionalmente justificar nossos princípios lógicos, se a própria possibilidade de justificação racional os pressupóe? Qual argumento racional poderia ser usado, para convencer um interlocutor litigante de que um conjunto de regras básicas é a correta, se todo argumento tem que ser, desde o início, baseado em um conjunto aceito de regras de inferência? Como poderíamos usar a razão para fundar os princípios mais básicos, sem circularidade e sem regressos ao infinito? Como seria possível argumentar na escolha de princípios básicos de um sistema lógico (claro, se for realmente possível falarmos de escolha)? Essas questóes abordam um antigo, mas ainda controverso tópico em relação à natureza da lógica e da nossa racionalidade. Hoje, o problema sobre justificação se torna ainda mais complicado, porque nós observamos uma profusão de sistemas de lógicas não clássicas legítimos e bem-estabelecidos, os quais desafiam a tradição filosófica clássica. O dogmatismo realista parece nos comprometer com a visão monista difícil de ser defendida no horizonte contemporâneo, com uma incrível pluralidade de lógicas diferentes (e incompatíveis).

Se pensarmos a razão e, por conseguinte, a lógica composta por jogos, ou seja, por atividades regradas, imersas em quadros heterogêneos de autorizaçôes e permissóes de indivíduos inseridos em comunidades, temos uma explicação do pluralismo lógico, ao destacar o âmbito da prática, da ação e de moves na lógica, devolvendo a ela o caráter interpessoal e dinâmico que tinha na retórica e dialética antigas, segundo defendido nos trabalhos de Dos Santos (2013) e de Dutilh-Novaes (2012).

Nós podemos raciocinar legitimamente de maneira muito diferente, em períodos diferentes e sob circunstâncias e pressōes diferentes. Essa visão social da racionalidade traz uma acepção mais holista de sistemas lógicos, porque devemos reconhecer que não há jogos sem regras e não há regras sem jogos. A par disso, é relevante verificarmos que uma consequência dessa proposta é que não precisamos justificar um jogo ou fundá-lo em alguma coisa externa a 
ele, especialmente em uma realidade transcendente inerte causalmente, como preconiza o dogmatismo realista.

Em um sentido filosoficamente significativo, jogos são autônomos, tanto em relação a uma metafísica de essências ou de fatos na realidade quanto de aspectos estritamente fenomenológicos. Jogos não precisam descrever alguma coisa na realidade ou em qualquer lugar para serem legítimos, todavia, podem ser usados para explicitar as regras que articulam variados sistemas. Há ainda outros elementos filosóficos relevantes, nessa abordagem pragmatista de sistemas formais (porque antípodas do dogmatismo realista): a lógica seria uma atividade humana demasiado humana, isto é, não precisaríamos de um sujeito metafísico e/ou transcendental, nem de uma realidade de estado de coisas inatingíveis ou de verdades metafísicas eternas, mas de indivíduos em uma comunidade, engajados (deontologicamente) em alguma atividade cooperativa (como a linguagem), para constituirmos racionalidade.

Obviamente, essas comunidades possuem uma história e elas criam, às vezes, por conveniência e, outras vezes, por diversão, alguns sistemas de regras para disciplinar algumas atividades. Regras lógicas podem ser institucionais, mas depois de instituídas deveriam ser tomadas como tão objetivas quanto qualquer instituição pública. Assim, desvios no jogo ou nessas atividades reguladas não são falsos ou verdadeiros, porém, apenas sem-sentido. Nós usamos nossas regras, muitas vezes, como critério para medirmos a qualidade de nossas descriçóes de fenômenos frequentemente vagos, indeterminados e radicalmente privados. Os critérios eles mesmos não são verdadeiros nem falsos, porque não precisam representar nada na realidade; os critérios formam o sistema de referência pelo qual descrevemos as coisas como verdadeiras ou falsas.

Eventualmente, podemos remover ou acrescentar alguma regra a alguma atividade, mas criamos com isso um jogo novo que se assemelha ao anterior. Esse novo jogo pode se assemelhar ao jogo anterior, entretanto, não é mais o anterior. Isso espelha adequadamente, por exemplo, uma intuição contemporânea a respeito da imensa pluralidade de sistemas lógicos: não dispomos, por exemplo, de um sistema dedutivo, mas de famílias de sistemas dedutivos, assim como não temos, por exemplo, uma lógica modal, contudo, famílias de lógicas modais, as quais podem ser agrupadas em diferentes classes por se assemelharem em algumas regras, resultados e em princípios aceitos ou rejeitados. 
A controvérsia sobre a correçáo de alguns princípios lógicos pode ser parcialmente resolvida, pela perspectiva pragmatista defendida por este trabalho, ao reconhecermos que palavras que designam operadores lógicos podem ter vários usos e objetivos diferentes, em práticas diferentes. A aceitabilidade de axiomas e do vocabulário lógico em um jogo inferencial depende de qual uso nós temos em mente, com qual audiência estamos tratando e a qual público pretendemos apresentar uma prova. Nesse sentido, não precisamos nos engajar com a ideia dogmática de que há uma única lógica correta, ou melhor, um único jogo correto, no entanto, podemos aceitar a seminalidade (e desafios) de dispormos de várias famílias de sistemas lógicos (jogos) distintos.

Essa discussão também pode ser remetida a um desenvolvimento propriamente wittgensteiniano (1969) do estatuto das assim-chamadas proposiçóes moorianas, como aponta Moyal-Sharrock (2004, 2005). Moore (1959) usa "eu sei que" conectado a diferentes proposiçôes empíricas, para desafiar o idealista e o cético. Alguns exemplos dessas proposiçôes de Moore são: "eu sou um ser humano", "existem outros seres humanos", "eu tenho um cérebro", "eu nunca estive fora do planeta”, "eu nunca estive na lua”, "eu tenho duas mãos", "todo ser humano tem um cérebro". Wittgenstein, em seu "Sobre a Certeza" (OC), questiona como nós aprendemos essas "verdades". A verdade das proposições de Moore é certamente não a priori e não é garantida pela verificação, afinal, ninguém nunca verificou se todos os seres humanos possuem de fato um cérebro, por exemplo. A verdade dessas proposiçóes especiais não parece residir em uma indução formal, porque não parecem ser baseadas em uma generalização tampouco (se for, é fundamentada em uma generalização com muito poucos espécimes).

Duas propriedades dessas proposiçóes de Moore chamam imediatamente a atenção, para Wittgenstein. Primeiro, elas são requeridas para se investigar a verdade de outras proposiçôes e, segundo, elas parecem ser isentas de dúvida. Nós não articulamos comumente essas “verdades", porém, também não aceitamos a sua (logicamente) possível falsidade. De fato, central para todas elas é o fato de elas desempenharem um papel especial de regra (OC 95), que as torna imunes a ataques céticos. De acordo, proposiçôes como "eis aqui a minha mão", em cenários como o de Moore, "ninguém nunca esteve na lua" (por volta de 1949), "o planeta começou a existir há muito tempo", "existem objetos físicos" são regras ou normas de descrição (OC 167, 321). 
Em outras palavras, justificação, dúvida e conhecimento só são possíveis dentro dos limites determinados por tomarmos algumas regras como garantidas em nossas práticas regradas ou jogos, porque elas desempenham um papel regulativo, normativo. Analogamente, normas públicas devem ser estáveis para a manutençáo de nossa racionalidade, assim como as regras de jogo devem permanecer estáveis, para que o jogo seja performado. Duvidar dessas regras básicas implicaria a paralisia do próprio jogo, assim como duvidar de algumas normas poderia paralisar nossas atividades racionais. $\mathrm{Na}$ interpretação de Wittgenstein, as proposiçóes de Moore são especiais, mas não por serem proposiçóes metafísicas, verdadeiras a priori.

Contudo, elas não são descrições tampouco. (Aqui vemos novamente o argumento do falso dilema operando.) As proposiçôes especiais de Moore nem compartilham uma forma lógica em comum (em verdade, elas todas possuem a forma de proposiçóes empíricas) nem um conteúdo semântico comum. Elas não são dubitáveis em função de seu papel normativo especial em nossas práticas regradas. Esse papel especial as faz proposiçóes da lógica. Esse papel poderia ser outro e poderia ser mudado. Nós somos educados por elas e através delas. Em caso de conflitos radicais em lógica, nós também devemos iniciar o litigante em novos procedimentos, interesses e visóes, ao mudar sua imagem de mundo.

A ideia decisiva é que nós temos uma fundação para nossas práticas racionais, entretanto, sem o dogmatismo realista. Em alguns cenários e situaçóes, o oposto de algumas proposiçóes que desempenham o papel de regras para nossos jogos ou práticas regradas não é nunca considerado, uma vez que devem permanecer sólidas, para que nossas atividades sejam empreendidas. Aqui náo se trata de um conteúdo proposicional representando estruturas abstratas independentes da realidade, mas os modos a partir dos quais agimos e julgamos tornam algumas coisas como fora de consideração ou indubitáveis.

Assim, pode-se motivar a transiçẫo da discussão do Wittgenstein tardio acerca do estatuto das proposiçóes de Moore para a lógica, ao enfatizarmos a analogia entre elas e princípios lógicos. Ambos são requeridos para investigar o sentido e a verdade de outras proposiçôes. Elas são usualmente isentas de dúvida, porque alguma coisa deveria permanecer fixa, caso contrário, nossas investigaçôes seriam minadas ou paralisadas. Em jogos, ou práticas regradas, algumas coisas deveriam permanecer inabaláveis, tomadas como sólidas e seguras. Note-se que várias proposições de Moore são consideradas óbvias, assim como princípios da lógica são, com frequência, apresentados na 
literatura. A recusa ou rejeição deles é com frequência tomada imediatamente como algo insano, não apenas como algo falso, visto que não abriríamos mão deles em função de sua força normativa em nossas práticas regradas. Essa impressão de solidez não deveria impossibilitar a ideia de que leis lógicas, assim como as proposiçôes de Moore, poderiam ser revisadas. A sua revisão deveria ser pensada como um tipo especial de conversão (PEREIRA, 2006).

\section{ConsideraçốES Finais}

Nesse contexto de discussão pragmatista sobre a natureza da racionalidade, em geral, e da lógica e de nossas práticas inferenciais, em especial, destacamos o uso de certas noções deontológicas, como as de proibição e autorização. Tais noçôes não estão, em um sentido filosoficamente relevante, no mundo, independentes de indivíduos engajados em práticas públicas em uma comunidade. Com isso em mente, é mais natural observarmos a plausibilidade das (provocativas) propostas normativas de Wittgenstein sobre a natureza da lógica, a saber: assim como sistemas de medidas não estão no mundo, isto é, reais e independentes de práticas humanas, a lógica também não está "aí fora". Os dois, sistemas de medição e sistemas lógicos, não devem ser justificados por qualquer realidade independente ou por uma estrutura a priori e universal da cognição, mas devem poder ser justificados pela estabilidade de nossas práticas e acordos. Se lógica puder ser redutível a uma esfera normativa de instruçóes para práticas - e a proposta wittgensteiniana e brandomiana a respeito de jogos é um bom candidato para desenvolver essa proposta -, então a lógica não é independente do mundo de comunidades humanas.

A normatividade que acompanha a noção de jogos representa uma revolução antropológica na discussão da natureza da lógica, uma vez que traz o pragmatismo de Wittgenstein e de Brandom ao centro da discussão contemporânea sobre a natureza da racionalidade, em uma plataforma contrária ao dogmatismo realista. 
SILVA, M. Against the realist dogmatism: notes on agreements and games. Trans/form/ ação, Marília, v. 44, n. 3, p. 287-312, Jul./Set., 2021.

\begin{abstract}
This paper discusses the existence of rules and criteria independent of our discursive practices by using Brandom's philosophy and Wittgenstein's philosophical development. For that, it examines the normativity of logic, especially facing the challenge of the diversity of non-classical logics and motivates that its constitution should be based on an analogy with games. This renders a pragmatist alternative to a realist sort of dogmatism. I then defend, using this pragmatist approach inspired in the notion of games and agreements, that it is not the objectivity of discourse that makes possible the normativity of our practices, but on the contrary, it is the intrinsic normativity of our practices, its set of authorizations and prohibitions, that should ground the rationality of our discourse.
\end{abstract}

Keywords: Wittgenstein. Brandom. Normativity. Pragmatism. Games.

\title{
REFERÊNCIAS
}

BEALL, J.; RESTALL, G. Logical pluralism. Australasian Journal of Philosophy, v. 78, p. 475-493, 2000.

BEALL, J.; RESTALL, G. Defending logical pluralism. Logical Consequence: Rival Approaches Proceedings of the 1999 Conference of the Society of Exact Philosophy, Stanmore: Hermes, 2001. p. 1-22.

BEALL, J.; RESTALL G. Logical Pluralism. Oxford: Oxford University Press, 2006.

BRANDOM, R. Making It Explicit: Reasoning, Representing, and Discursive Commitment. Cambridge, MA: Harvard University Press, 1994.

BRANDOM, R. Articulating Reasons. Cambridge, MA: Harvard University Press, 2000 .

BRANDOM, R. Between Saying and Doing: Towards an Analytic Pragmatism. Oxford: Oxford University Press, 2008.

BROUWER, L. Over de Grondslagen der Wiskunde. Ph. D. thesis, Universiteit van Amsterdam, Amsterdam, 1907, p. 11-101 [English translation in BROUWER, 1975].

BROUWER, L. De Onbetrouwbaarheid der Logische Principes. Tijdschrift voor Wijsbegeerte, v. 2, p. 152-158, 1908 [English translation in VAN ATTEN; SUNDHOLM 2017. , p. 107-111. An older English translation is in Brouwer, 1975].

CARNIELLI, W.; RODRIGUES, A. Towards A Philosophical Understanding Of The Logics Of Formal Inconsistency. Manuscrito, v. 38, p. 155-184, 2015. 
CARNIELLI, W.; RODRIGUES, A. On the Philosophy and Mathematics of the Logics of Formal Inconsistency. In: BEZIAU, J.-Y.; CHAKRABORTY, M.; DUTTA, S. (ed.). New Directions in Paraconsistent Logic. New Delhi: Springer, 2016. p. 57-88.

CARNIELLI, W.; RODRIGUES, A. An epistemic approach to paraconsistency: a logic of evidence and truth. Synthese, v. 196, p. 3789-3813, 2017.

CARNIELLI, W.; RODRIGUES, A. On epistemic and ontological interpretations of intuitionistic and paraconsistent paradigms. Logic Journal of the IGPL, v. 29, n. 4, p. 569-584, 2019a.

CARNIELLI, W.; RODRIGUES, A. Inferential semantics, paraconsistency, and preservation of evidence. In: BA,SKENT, C.; FERGUSON, T. M. (ed.). Graham Priest on Dialetheism and Paraconsistency. Dordrecht: Springer, 2019b.

CUTER, J. V. Números e cores. Dois Pontos. Curitiba, São Carlos, v. 6, n. 1, p. 181 193, abr. 2009.

CUTER, J. V. Uma fenomenologia sem métrica. In: CARVALHO, M. et al. Fenomenologia, análise e gramática: comentário às observaçóes filosóficas de Wittgenstein parte 1. São Paulo: Mundaréu, 2017.

DA COSTA, N. C. A. Nota sobre o conceito de contradição. Anais da Sociedade Paranaensede Matemática, v. 1, p. 6-8, 1958.

DA COSTA, N. C. A. Observaçôes sobre o conceito de existência em matemática. Anais da Sociedade Paranaense de Matemática, v. 2, p. 16-19, 1959.

DA COSTA, N. C. A. On the theory of inconsistent formal systems. Notre Dame J Form L, v. 15, p. 497-510, 1974.

DUMMETT, M. Frege: Philosophy of Language. Cambridge, Mass.: Harvard University Press, 1991.

DUTILH-NOVAES, C. A Dialogical Account of Deductive Reasoning as a Case Study for how Culture Shapes Cognition. Journal Of Cognition And Culture, v. 13, n. 5, p. 459-482, 2012.

ENGELMANN, M. Wittgenstein's Philosophical Development: Phenomenology, Grammar, Method and the Anthropological View. Hampshire: Palgrave Macmillan, $2013 a$.

ENGELMANN, M. Wittgenstein's "Most Fruitful Ideas" and Sraffa. Philosophical Investigations, v. 36, n. 2, p. 155-178, abr. 2013 b.

FREGE, G. The Foundations of Arithmetic. Trad. de J. L. Austin. Evanston: Northwestern University Press, 1889/1978.

HACKER, P. Insight and Illusion: themes in the Philosophy of Wittgenstein. Oxford: Clarendon Press, 1986. 
HACKER, P. Kant and Wittgenstein: The matter of transcendental arguments. In: VENTURINHA, N. (ed.). The Textual Genesis of Philosophical Investigations. New York: Routledge, 2013.

HEYTING, A. Prize essay on the formalization of intuitionistic logic. 1928.

[Expanded and revised version published as HEYTING, 1930a, HEYTING, 1930b, HEYTING, 1930c].

HEYTING, A. Die formalen Regeln der intuitionistischen Logik I. Sitzungsberichte der Preussischen Akademie der Wissenschaften, p. 42-56, 1930a.

HEYTING, A. Die formalen Regeln der intuitionistischen Logik II. Sitzungsberichte der Preussischen Akademie der Wissenschaften, p. 57-71, 1930 b.

HEYTING, A. Die formalen Regeln der intuitionistischen Logik III. Sitzungsberichte der Preussischen Akademie der Wissenschaften, p. 158-169, 1930c.

HUTTO, D.; MYIN, E. Radicalizing Enactivism: Basic Minds Without Content. MIT Press, 2013.

LEWIS, D. Scorekeeping in a Language Game. Journal of Philosophical Logic, v. 8, n. 1, p. 339-359, 1979.

MARCOS, J. Logics of Formal Inconsistency. 2004. Tese (Doutorado) - Departamento de Filosofia. Universidade Estadual de Campinas, Instituto de Filosofia e Ciências Humanas, Campinas, 2004.

MARCOS, J. Wittgenstein \& Paraconsistência. Principia, v. 14, n. 1, p. 135-173, 2010.

MOORE, G. E. Philosophical Papers. Londres: Allen and Unwin, 1959.

MOYAL-SHARROCK, D. Understanding Wittgenstein's On Certainty. New York: Palgrave Macmillan, 2004.

MOYAL-SHARROCK, D. Readings of Wittgenstein's On Certainty. New York: Palgrave Macmillan, 2005.

PEREIRA, L. C. Breves consideraçóes sobre o niilismo e o revisionismo na lógica. $\mathbf{O}$ que nos faz pensar, n. 20, p. 91-99, dez. 2006.

PRIEST, G.; TANAKA, K.; WEBER, Z. Paraconsistent Logic. The Stanford Encyclopedia of Philosophy. Disponível em: http://plato. stanford.edu/archives/spr2015/ entries/logicparaconsistent/ Acesso em: 23 jun. 2020.

RORTY, R. Philosophy and the Mirror of Nature. Princeton, NJ: Princeton University Press, 1979.

SANTOS, L. H. dos. A Essência da Proposiçáo e Essência do Mundo: Estudo Introdutório do Tractatus Logico-philosophicus. São Paulo: EdUSP, 2001.

SANTOS, L. H dos. Retórica versus dialética: divagação a propósito do Górgias de Platão. Revista Analytica, Rio de Janeiro, v. 17, n. 2, p. 249-263, 2013. 
SHAPIRO, S. Varieties of Logic. Oxford: Oxford University Press, 2014.

SILVA, M. Wittgenstein, Cores e Sistemas: aspectos lógico-notacionais do colapso do Tractatus. Revista Analytica, v. 15, n. 2, 2011.

SILVA, M. Holismo e Verofuncionalidade: sobre um conflito lógico-filosófico essencial, Philósophos, v.18, n. 2, p. 167-200, jul./dez. 2013.

SILVA, M. Notas sobre o papel lógico-normativo da noção de medida. Problemata: R. Intern. Fil. v. 6, n. 3, p. 247-263, 2015.

SILVA, M. Verificacionismo, Expressivismo, Inferencialismo: Uma leitura normativa. Veritas, v. 65, n. 3, 2020.

WITTGENSTEIN, L. Philosophical Investigations. Translated by G. E. M. Anscombe. Oxford: Basil Blackwell, 1953. (PI)

WITTGENSTEIN, L. On Certainty. Edição bilíngue. G. H. von Wright \& G. E. Anscombe (org.). Londres: Basil Blackwell, 1969. (OC)

WITTGENSTEIN, L. Wittgenstein und der Wiener Kreis (1929-1932). Werkausgabe Band 3. Frankfurt am Main: Suhrkamp, 1984. (WWK)

Recebido: 08/4/2020

Aceito: 30/12/2020 
SILVA, M. 